\title{
Capoeira angola em corpos estrangeiros: reestruturação de conhecimentos e de relações através da performance ritual
}

Cecilia Tamplenizza ${ }^{1}$

\section{Resumo}

Para a tese de doutorado realizei um estudo etnográfico interpretativo e reflexivo, baseado em minha experiência de aprendizado da capoeira angola no Grupo de Capoeira Angola Pelourinho Gcap, situado em Salvador Bahia, e nas relações que teci com o grupo. Nessa pesquisa, sugeri que a capoeira angola, para esse grupo, é um complexo ambiente de comunicação e criação ritual. Sua performance é fundamentada em um repertório aberto de poesias cantadas e desenhadas com o corpo. Um jogo corporal, musical e de relações entre os capoeiristas do grupo. Uma poética em resistência que difunde práticas baseadas em uma tradição ou ancestralidade afro-descendente, com uma forte conotação política no Brasil. A partir dessas premissas, nesse artigo, proponho uma reflexão sobre como alguns de nós italianos estamos reinterpretando a capoeira em um contexto externo aos processos de luta e resistência dos descendentes dos africanos no Brasil. Para isso, além de minha pesquisa de campo autoetnográfica, me valho-me de entrevistas e discussões travadas com outros capoeiristas italianos, provenientes de diversas cidades, do norte ao sul da Itália, que praticam capoeira há mais de 15 anos e que participam de grupos de capoeira angola ligados à linhagem de mestre Pastinha. Chegando na Itália por caminhos independentes, a capoeira angola se tornou uma prática que diz promover a libertação. Uma forma de transmissão de meios alternativos de se relacionar, criar, se organizar.

\section{Palavras-chave}

Capoeira angola. Performance. Ritual. Corpo. Interculturalidade.

\begin{abstract}
For my doctoral thesis, I conducted an interpretive and reflective ethnographic study, based on my experience of learning capoeira angola in the Grupo de Capoeira Angola Pelourinho - Gcap, located in Salvador Bahia, and on the relationships I had with the group. In this research, I suggested that capoeira angola, as I practice in this group, is a complex environment of communication and ritual creation. Her performance is based on an open repertoire of poetry sung and drawn with the body. A game of body, music and relationships between the capoeiristas. A poetics in resistance that spreads practices based on an Afro-descendant tradition or ancestry, with a strong political

\footnotetext{
${ }^{1}$ Doutora em Antropologia Cultural e Social da Universidade Statale Bicocca de Milão. E-mail:
} ceciliatamplenizza@gmail.com.
\end{abstract}


connotation in Brazil. Based on these premises, in this article, I propose a reflection on how some of us, Italians, are reinterpreting capoeira in an external context to the processes of struggle and resistance of African descendants in Brazil. For this, in addition to my autoethnographic field research, I use interviews and discussions with other Italian capoeiristas, from different cities, from the north to the south of Italy, who practice capoeira for over 15 years and who participate in groups of Capoeira Angola linked to mestre Pastinha's lineage. Arriving in Italy by independent paths, capoeira angola became a liberation practice. A way of transmitting alternative means of relating, creating, organizing.

\section{Keywords}

Capoeira angola. Performance. Ritual. Body. Interculturality.

\section{Introdução}

Para a tese de doutorado realizei um estudo etnográfico interpretativo e reflexivo, baseado em minha experiência de aprendizado da capoeira angola no Grupo de Capoeira Angola Pelourinho - Gcap, situado em Salvador Bahia, e nas relações que teci com o grupo ${ }^{2}$. O Gcap é um grupo de capoeira angola fundado em 1980 por Pedro Moraes Trindade, mestre do grupo, que desde menino frequentou o Centro Esportivo de Capoeira Angola Pelourinho de mestre Vicente Pastinha, que na época era já idoso. Moraes aprendeu com os mestres João Pequeno e João Grande e, fora do Centro, com vários outros mestres hoje menos conhecidos, como Tonho de Hilda, do bairro da Massaranduba ${ }^{3}$.

O Gcap foi fundado para dar continuidade, fora de Salvador, à prática da capoeira angola que Moraes conhecia, diferente de outros estilos que havia encontrado em sua ida à Rio de Janeiro como membro dos Fuzileiros Navais. O grupo propunha uma visão política da capoeira, engajada com as questões raciais, sociais e culturais no Brasil. Preocupação que já estava organicamente

\footnotetext{
2 Cabe lembrar que de um ponto de vista interpretativo, o "campo" não é concebido apenas como uma realidade física representável que, portanto, é autônoma à pesquisa e ao pesquisador, mas é entendido como uma construção fictícia, uma narrativa, que existe exclusivamente porque é contextual ao trabalho do pesquisador. A definição do campo deve ser empreendida como uma atividade complexa que serve de suporte para a compreensão e a reformulação dos dados recolhidos, privilegiando a dimensão subjetiva - não determinista e representável - do comportamento humano.
}

${ }^{3}$ Para aprofundar a história do Gcap e do mestre Moraes ver TAMPLENIZZA (2017). 
presente nas gerações anteriores de angoleiros e que, com o passar do tempo e com a participação de alguns membros do grupo em cursos universitários, tomou um caráter mais formal ${ }^{4}$. Desde sua fundação no Rio de Janeiro, até a volta para Salvador, poucos anos depois, e com a expansão em outros estados e países, o Gcap tem apresentado e pesquisado a capoeira angola como uma arte afro-brasileira em resistência. A capoeira angola, para esse grupo, é um complexo ambiente de comunicação e criação ritual. Sua performance é fundamentada em um repertório aberto de poesias cantadas e desenhadas com o corpo. Um jogo corporal, musical e de relações entre os capoeiristas do grupo. Uma poética em resistência que difunde práticas baseadas em uma tradição ou ancestralidade afro-descendente, com uma forte conotação política no Brasil.

Ao refletir sobre as culturas como ambientes de relação, confrontação e diálogo, me dedico a uma pesquisa etnográfica multi-situada, que se desenvolve entre o norte da Itália, meu país de origem, e Salvador, Bahia, onde pesquiso capoeira há dez anos. Trato de fluxos, de encontros reais e virtuais, de narrativas e suas reinterpretações. Conheci a capoeira na Itália e ali comecei sua prática, depois de mais ou menos 5 anos comecei minhas pesquisas em Salvador que culminaram com a participação no Gcap, escolhido por sua influência política no mundo da capoeira. Além de realizar trabalho de campo, me tornei aluna e membro do Gcap, participando e contribuindo ativamente à organização do grupo e às reflexões ali produzidas. Nesse encontro, desde o começo, me apresentei como pesquisadora e procurei sempre que possível compartilhar, com o mestre e os outros membros, as minhas perguntas de pesquisa, valorizando um conhecimento polifônico e relacional. De volta para Itália, compartilhei com os capoeiristas italianos minhas experiências e debati com alguns deles aspectos centrais das relações tecidas através da capoeira, que apresento sumariamente neste artigo.

Do ponto de vista metodológico considero a participação como uma estratégia de pesquisa que favorece o encontro. Evidenciando que, como lembra o antropólogo Roberto Cardoso de Oliveira (1998, p. 26), o homem não pensa sozinho, em um monólogo solitário, mas o faz socialmente, no interior de uma [ou mais de uma] "comunidade de comunicação" e "de argumentação". A pesquisa participativa favorece esse encontro de comunidades. Com esse intuito, ao longo do artigo, uso a primeira pessoa plural evidenciando meu envolvimento ativo com as questões apresentadas e a existência de tratos comuns entre os capoeiristas italianos com os quais tenho

\footnotetext{
${ }^{4}$ Sobre esse tema ver Tamplenizza (2017).
} 
interagido. Resulta uma escrita talvez um pouco geral na qual não se percebem as especificidades de cada um, centrada naquilo que os entrevistados dizem fazer mais que naquilo que fazem. Essa decisão foi tomada com o intuito de realçar pontos em comum entre os capoeiristas e reservar outro lugar para aprofundar o tema a partir de outras perspectivas.

Com base nessas premissas, proponho uma reflexão sobre como alguns de nós italianos estamos reinterpretando a capoeira em um contexto externo, mas envolvido, aos processos de luta e resistência dos descendentes dos africanos no Brasil. Em um contexto sócio-cultural diferente, as artimanhas escondidas no ritual da capoeira estão sendo coligadas à nossa realidade social e são apreendidas como ensinamentos para, por exemplo, enfrentar outras injustiças sociais e dificuldades relacionais.

É importante ainda sublinhar que a chegada da capoeira na Itália aconteceu de forma não linear, muitas vezes desligada dos conflitos e relações da capoeira no Brasil. Essa desconexão pode ter sido causa de certo etnocentrismo implícito dos italianos nas relações com os capoeiristas brasileiros, iniciando novos conflitos. Para entender isso, é suficiente pensar que a própria distinção entre capoeira angola, regional e contemporânea (e outras...) só começou a fazer sentido muito recentemente na Itália e ainda está mais atrelada à questões estéticas ou de mercado. No entanto, no Brasil a diferença de cunho político é mais presente, a situação se tornou cada vez mais complexa, com divisões e distanciamentos entre as mesmas modalidades de capoeira, ou parceria e uniões entre modalidades diferentes.

\section{A chegada da capoeira na Itália}

A capoeira se apresentou oficialmente ao público italiano nos anos de 1980, em grandes shows teatrais como o "Oba Oba" em que os capoeiristas eram descritos como "dançarinos ritmadores". Nas primeiras edições desses espetáculos, as bailarinas de samba tomavam a frente da cena. A partir de 1995, o destaque especial foi dedicado aos capoeiristas, descritos por suas qualidades atléticas e corpos sensualizados: “"Uma atração ao mesmo tempo exótica - a arte marcial que descende da cultura negra dos escravos de Angola (CRIPPA, 21 dic. 1995, p. 51) - erótica - em cena as nádegas nervosas dos meninos, os incríveis acrobatas da capoeira - e atlética - com piruetas sem parar. Um espetáculo "que promove o estereótipo, todo o ritmo e sexo do Brasil..." (PORRO, 30 dic. 1995, p. 39, trad.minha). 
Esses espetáculos eram chamados de "folclóricos", mas se distanciavam da capoeira pesquisada pelos estudos do folclore, por pesquisadores como Arthur Ramos (1936, 1956), Edison Carneiro (1991, 1974, 1977), Luis da Câmara Cascudo (1967) entre outros que tratavam dessa arte 'folclórica' como sinônimo de 'cultura popular'. Esses shows eram o resultado da transformação e junção de diversos elementos da cultura popular brasileira, com outras formas de espetáculo, em uma proposta que satisfazia o gosto internacional. Um formato pensado para um público global e economicamente interessante. A associação do termo 'folclórico' a esses tipo de companhias levou alguns mestres das culturas populares que até então tinham aceito esse termo para se auto definir, a adotá-lo como termo depreciativo, símbolo de uma forma de capoeira esvaziada de suas componentes políticas e de organização periférica, sóciocultural.

A partir dos anos de 1990, além desses grandes espetáculos, as artes marciais, os festivais de música e os espetáculos de dança foram os canais de acessos da capoeira na Itália, ainda sem estar propriamente ligada ao ritual da roda, o ritual em círculo onde acontece a capoeira, mas recontextualizada como uma linguagem corporal-artística que podia ser fundida com outras técnicas e linguagens, a exemplo da brake dance e da contact improvisation, e também com outras modalidades de luta. Os primeiros capoeiristas italianos começaram treinando uma capoeira chamada "contemporânea" que, com a pretensão de se manter fora do debate e da prática político-ideológica ligada a divisão angola/regional, propunha a capoeira como sendo uma só. Essa capoeira era ensinada pela maioria em ginásios e clubes esportivos, como uma atividade física para manutenção da forma e como atividade para que os italianos pudessem se distrair após o trabalho.

No início, praticamos um tipo de capoeira que era muito mista. Uma capoeira, que provavelmente para se enraizar em nosso território, na Itália, infelizmente, ainda precisava se espetacularizar em alguns aspectos e, por isso, foi uma capoeira mista. Fazíamos movimentos diferentes, adotávamos as cordas, em seguida, o nosso professor eliminou as cordas e esta confusão levou-nos um pouco de perplexidade (FABRIZIO, 2015, trad.minha).

Essa confusão caracterizou a experiência dos primeiros capoeiristas italianos. Os festivais de música foram outro contexto em que a capoeira se difundiu oficialmente, ligada a grupos de folk, world music ou música étnica. Assim como o termo "folclore", também a definição desses estilos musicais è 
complexa, ao me referir a eles entendo, aquele segmento musical e discográfico que inclui registro da música tradicional, fusões desse repertório com outros gêneros ocidentais como o pop, o rock, a música clássica e eletrônica. Bem como misturas de ritmos, música e instrumentos de diversas partes do mundo ${ }^{5}$.

Nesses Festivais na Itália são realizados os primeiros cursos e demonstrações que começam a mostrar, de uma maneira ainda bastante ingênua e comercial, características ligadas a uma dimensão sócio-política e ritual da capoeira.

\begin{abstract}
“Centenas de jovens, apaixonado e curioso, puderam falar diretamente com os músicos e participar a cursos de Capoeira dança brasileira, que era na verdade um tipo de arte marcial praticada por negros escravos, mascarada de dança, porque a eles era estritamente proibidos de vir a golpes: de modo que, quando os gendarmes os surpreendiam lutando, os escravos começavam a dançar" (COLOSSEO, 26 out 1996, trad.minha, negrito meu).
\end{abstract}

O discurso do corpo, negro, forte e sensualizado è substituído pela imagem do escravo que luta capoeira para se libertar do seu dono: "dança acrobática [...] Imita o movimento de escravos, que para se libertar das cadeias, usavam uma faca chamada precisamente capoeira, segurada entre os dedos dos pés" (MARTORANA, 9 jul.1994, p. 51, trad. minha).

A capoeira angola, modalidade que pesquiso, chegou na Itália no final dos anos de 1990 para se contrapor a uma visão comercial da capoeira dos espetáculos. Chegou na Itália por caminhos independentes e se tornou uma porta de acesso para que os italianos, em geral pouco informados sobre o período da escravidão atlântica, pudessem saber mais sobre a história do Brasil e sobre formas de se relacionar, criar, se organizar, através de uma linguagem diversamente eficaz da comunicação falada. Além de uma prática física, se propõe como uma filosofia de vida.

É importante destacar que na mesma época, a capoeira contemporânea revestiu um papel predominante para a difusão do ritual de capoeira, de argumentos históricos atrelados à sua prática e inclusive na difusão da existência de diferentes modalidades de capoeira, valorizando os conhecimentos dos mestres angoleiros no Brasil. Certos grupos de capoeira regional e contemporânea também se propõem como filosofias de vida,

\footnotetext{
${ }^{5}$ Para aprofundar esse assunto, no Brasil Pinto (2008, p. 11) aponta para a relação entre world music e música popular.
} 
promovendo diversas relações e conhecimentos. Não trato desse tema nesse artigo, pois não tem sido parte do meu objeto de estudo, mas existem outras pesquisas que se dedicaram especificamente a esses outros estilos.

\section{Um novo contexto, uma filosofia de vida}

Em conversas com alguns capoeiristas italianos que praticam capoeira há mais de 15 anos perguntei e discuti sobre seus interesses e relações com a capoeira angola, procurando entender o que os apaixonou a ponto de dedicarem suas vidas a esse conhecimento. Defini o grupo de entrevistados a partir de sua insistência na prática com a capoeira angola e em seu interesse por vertentes ligadas à capoeira angola vinda de Salvador, Bahia. Em específico, pessoas que participaram às duas edições do evento do Gruppo di Capoeira Angola Cremona ${ }^{6}$ nos anos de 2015 e 2016, nas quais foi convidado o mestre baiano Pedro Moraes Trindade, fundador e leader do Grupo de Capoeira Angola Pelourinho - GCAP. Essa escolha é motivada pelo meu interesse em tratar da reelaboração dos mesmos ensinamentos em contextos culturais diferentes.

Trata-se de cinco mulheres e seis homens, pessoas que como eu fazem e pesquisam capoeira há mais de quinze anos. Algumas delas conheceram o Brasil e outras não. Todas vivem na Itália e provém de diversas regiões do país. Pertencem a diversos grupos de capoeira. Elas têm hoje entre os 38 e os 51 anos de idade. A grande maioria possui estudos superiores completos, em diversas áreas. Todas elas têm em comum a paixão, até então inesgotável, apesar das dificuldades impostas pelo distanciamento social devido à pandemia por Covid-19, pela capoeira angola.

A chegada da capoeira na Itália está em parte atrelada ao mundo da contracultura, dos espaços culturais ocupados, lugares onde os brasileiros e o interesse pelas suas culturas encontraram mais espaço e aceitação. Num

${ }^{6}$ Cremona, a cidade que hospedou esses eventos, é situada no norte da Itália, na província de Lombardia, e possui 71.901 habitantes, dos quais 10.365 são estrangeiros regularmente residentes, 2.557 originários da África e 57 do Brasil. Cremona é uma cidade com uma forte influência cultural oriental e africana e é, ao mesmo tempo, famosa por sua arquitetura medieval, românica, continuamente adaptada com elementos góticos, renascentistas e barrocos. Cremona é também famosa por ser a cidade natal do compositor Claudio Monteverdi e do luthier Antonio Stradivari. Em 2012, dois anos antes do reconhecimento da capoeira, a Unesco incluiu o artesanato tradicional do violino de Cremona entre os patrimônios orais e imateriais da humanidade. Dados demográficos de 2015, disponíveis em

http://demostat.provincia.cremona.it/demo/demohome.php e http://www.tuttitalia.it/lombardia/26-cremona/statistiche/cittadini-stranieri-2016, consultado em 20 jan. 2017. 
primeiro momento, o discurso sobre a capoeira como luta de libertação dos escravizados no Brasil despertou o interesse das pessoas que frequentavam esses ambientes. Porém, na maioria das vezes, segundo eles, a prática proposta não acompanhava o discurso verbal. Não havia uma identificação com a história política da capoeira. As informações que se tinham sobre tal temática eram poucas. Antes da internet ser difundida massivamente era muito difícil encontrar textos que falassem da cultura popular brasileira, dos personagens históricos e míticos que povoam as ladainhas e cantigas da capoeira, por exemplo.

Atraídos pelo novo discurso, diversos alunos de capoeira contemporânea procuraram a capoeira angola mas sentiram dificuldade por não encontrar um mestre ou professor capaz de lhes orientar. Por conta da necessidade de sobrevivência, alguns brasileiros começaram a ensinar capoeira na Itália, sem competências para isso, se aproveitando da curiosidade e da boa vontade dos jovens italianos. Segundo Alessandro, ao conhecer os primeiros angoleiros, a enganação se tornou evidente. "Depois, quando vimos os primeiros angoleiros, vimos que "Ah! Agora está claro!", nos contaram uma grande mentira e começamos a entender. Iniciamos a trabalhar a capoeira angola na forma que é hoje, com os mesmos princípios" (ALESSANDRO, 2015, trad.minha). Esse "começar a entender" é um momento muito significativo para a capoeira angola na Itália que, a meu ver, mais que falar da veracidade dos capoeiristas, mostra que a prática da capoeira iniciava a fazer sentido para os italianos, que passaram a construir uma identificação própria com ela, por vias de uma reinterpretação.

Com a chegada dos primeiros capoeiristas angoleiros, os italianos começaram entender que no Brasil existiam diversos estilos de capoeira, seja por um uso diferenciado da movimentação, mas especialmente por formas de organização e identidades políticas específicas. As possibilidades comerciais e a demanda crescente da capoeira angola na Itália, o interesse por esse trabalho interdisciplinar, capaz de atrair um público interessado na diversidade cultural, levaram, não somente os alunos italianos, mas também alguns capoeiristas brasileiros já mestres ou professores de capoeira contemporânea, a mudar de estilo e começar um percurso de pesquisa da capoeira angola. Aos poucos, muitos começaram a incluir em seu discurso a componente cultural e histórica da capoeira, atraindo um público mais vasto que aquele somente interessado na prática de ginástica.

Distante do contexto de luta dos afrodescendentes no Brasil e do ativismo do movimento negro, a imagem do capoeirista, negro, rebelde, estratega que 
luta, não só fisicamente, mas intelectualmente na tentativa de desconstruir e transformar o imaginário e a realidade deixada pelo sistema escravocrata da colonização, é tomada como símbolo de libertação de outras formas de opressão. Nesse momento da chegada da capoeira na Itália, cria-se um distanciamento, pouco claro, entre a imagem da capoeira como "luta de libertação" dos escravos e a atualidade dos capoeiristas no Brasil, seu engajamento político com a luta contra a desigualdade racial.

Desligada do contexto sócio-político brasileiro, das questões ligadas à cultura afrobrasileira, a prática cotidiana de uma capoeira angola, novamente misturada, resultado dos ensinamentos e técnicas, não somente de um mestre, mas de um conjunto de pessoas diferentes, começou a fazer sentido. Os envolvidos nesse processo foram jovens interessados com a diversidade cultural, com interesses de pesquisa mais filosóficos e comunitários. A curiosidade, a vontade de participar a algo diferente do estabelecido pelas mídias de massa e pelos circuitos comerciais, o desejo de se confrontar com outras culturas, a necessidade de se envolver em uma atividade que permitisse uma descoberta de si, através de uma prática ritual, são fatores que levaram todos os capoeiristas italianos com que conversei a se envolver com a capoeira. A capoeira se difunde como "arte de libertação".

\section{Um sistema de comunicação entre línguas e culturas diferentes}

O aprendizado de capoeira angola na Itália, mesmo que realizado com professores diferentes com estilos e interpretações peculiares da capoeira, tem proporcionado aos praticantes italianos algumas experiências e sensações de aprendizado comuns. Todos os entrevistados e inclusive eu passamos por caminhos parecidos. Primeiro o espanto, ou shock, uma sensação muito forte a nível emotivo e uma forte vontade de participar do ritual da capoeira. Porém, apesar da curiosidade e da vontade de aprender, o primeiro período de vivência com um grupo foi caracterizado pela falta de compromisso e por uma observação pouco atenta, superficial. Esse período de superficialidade foi tanto maior quanto menor a capacidade dos professores de ensinar e transmitir características interdisciplinares da capoeira angola.

A incompreensão linguística foi um dos primeiros entraves que precisamos ${ }^{7}$ resolver. No início do aprendizado, aprendemos as músicas sem entender o

\footnotetext{
${ }^{7}$ Adoto aqui a primeira pessoa plural, pois faço referências não somente aos capoeiristas italianos com os quais conversei, mas também a mim pela participação como aprendiz de capoeira e italiana.
} 
significado literário de corridos e ladainhas. Muitas vezes, sem saber a quem perguntar ou envergonhados por um ambiente novo, repetimos sons parecidos com as palavras, com a ideia de no mínimo estar contribuindo com a energia do canto. Assim, como quando éramos meninos e cantávamos músicas em uma língua inventada, simulando o inglês, por exemplo, emocionados pelo ritmo e pelo contexto social e midiático, não importava o significado das músicas que nos gostavam. Essa ingenuidade, talvez, tenha nos levado a nos emocionar por letras que com o passar dos anos descobrimos poucos interessantes ou até mesmo contrárias às nossas expectativas. No aprendizado da capoeira, Fabrizio lembrou essa situação de superficialidade:

Eu não falava uma palavra de português, me ajudou muito, entre outras coisas, a sorte de ter uma língua mãe próxima. Isso também foi uma questão de maturidade, talvez no início não aprofundava, repetia o que sentia, o italianizzava, "quem sabe, será isso...", então eu percebi o quanto lendo as palavras muda o significado e também é mais fácil aprender, porque muitas palavras são semelhantes ao Italiano. E assim que eu desenvolvi um pouco de português, o entendo, tento me expressar (FABRIZIO, 2015, trad.minha).

Aprender com a capoeira nos ensinou que para criar uma relação com outra cultura é necessário ir além da curiosidade, estudar e sair de uma zona de conforto que começa a incomodar, confundindo-se com desrespeito. Nesse processo, ficar presa à emoção, ao sentimento que nos faz sentir alegres e acreditar em um bem-estar envolvente. Não racionalizar e deixar de se perguntar mais sobre o que está sendo feito e transmitido, equivale a ficar preso a um preconceito, acreditando que o outro não tem nada a ensinar para além do superficial, da dança, da luta, do ritmo e dos instrumentos, diferentes, exóticos... A prática cotidiana e ritual da capoeira, nos faz compreender que, na maioria das vezes, quando nos confrontamos com outra cultura não é dela que queremos saber, mas do nosso estar bem, de comprazer nossa curiosidade, nossos interesses. Assim, sugere a fala de Marco L., o ritual da capoeira, baseado na repetição é um elemento fundamental para o diálogo intercultural: “as músicas, os corridos, serviram como viático para ... eu acho, que mesmo quando você não é, você se torna curioso, porque de tanto ouvir falar de certas coisas em algum momento você vai se questionar e se você é apaixonado por aquilo que faz é um processo bastante espontâneo" (MARCO L., 2016).

Todos nós fomos à procura de respostas para nossas perguntas, a fim de que não nos sentíssemos ignorantes. Neste percurso, descobrimos que era mais fácil 
ler o português escrito do que entendê-lo oralmente. Transcrevemos as músicas para, posteriormente, compreendê-las na vivência do ritual. Aprendemos a comunicar com pessoas de outros países através do português, ou uma sua versão simplificada, que se tornou uma nova "língua franca", não feita somente de palavras, mas também de movimentos, ritmos e situações.

Além de aprender a língua portuguesa, a capoeira nos levou a querer conhecer o Brasil. Mestre Baixinho (2015), um dos primeiros professores de capoeira na Itália, depois de ter observado seus alunos, percebeu que o interesse deles não era mais de frequentar o Brasil como turista, mas de entender a cultura e o meio social em que a capoeira tem sido cultivada, assim como conhecer os brasileiros e seus costumes. Ao morar no Brasil, com a missão de conhecer a capoeira, o estrangeiro começa a entender melhor a língua portuguesa e a compreender a capoeira como uma linguagem atrelada ao cotidiano do país. Conhecer o cotidiano dos brasileiros, sua cultura e comportamentos são experiências ricas para a capoeira, que proporcionam uma dimensão mais ampla dos seus significados, assim como a consciência do que lugar ocupa o estrangeiro na relação intercultural.

Além de criar relações e abrir possibilidades para conhecer outros países e favorecer o diálogo intercultural, o aprendizado da capoeira ofereceu aos italianos a possibilidade de criar uma nova relação com a música. Na Itália, o aprendizado musical é ligado aos cursos de música ou à educação musical durante o ensino fundamental, deixado ao acaso ou à sorte de se ter um bom professor. Mesmo assim, é um aprendizado desligado da vida cotidiana. A música é entendida principalmente como algo que se toca, se ouve ou se dança, executada ao vivo ou reproduzida por algum aparelho sonoro. Rituais cotidianos, em que o canto ou a música orientam o movimento do resto do corpo, não são muito difusos. Isso hoje só ocorre em rituais religiosos e em brincadeiras de crianças 8 .

Os capoeiristas italianos tivemos que aprender a relação de troca, que existe na capoeira, entre a parte musical e a parte física. Lembra Marco L. em sua conversa comigo: "É uma coisa muito peculiar, não é por nada óbvia" (MARCO L., 2016, trad.minha). Tivemos que descobrir e entender que a capoeira não é somente uma arte marcial, mas uma disciplina que compreende diversos aspectos, entre os quais a prática musical, que é fortemente interligada à parte física dos movimentos. "Não só porque se faz capoeira ao ritmo de música, mas

\footnotetext{
$8 \mathrm{Na}$ Itália, a associação entre música e cotidiano é ensinada em pequenas comunidades tradicionais, que procuram manter rituais e danças como parte da vida comunitária, sendo realidades pouco conhecidas nas grandes cidades.
} 
porque é parte da experiência do capoeirista, seja quando toca, claro, seja quando joga. Com isso, quero dizer que quando você se movimenta, o faz em base a um ritmo" (MARCO L., 2016, trad.minha). A capoeira nos ensinou que nossos corpos não simplesmente se movimentam mas o fazem seguindo ritmos: "pode ser devagar, ou rápido, se você tem pressa, corre, se não caminha, você está sempre se movendo em base a um ritmo. Mas, você não sabe porque o faz. Na capoeira esta coisa é explícita" (MARCO L., 2016, trad.minha). Além disso, diz Marco, tem a questão dos textos das cantigas, que transmitem diversas mensagens, tornando manifesta também a relação do ouvido com o movimento. No início do aprendizado, conta Marco:

Obviamente no início a presença da música, por quanto agradável, divertida e interessante permaneceu um pouco...como se fosse algo ao lado da prática da capoeira, porque para mim, que tinha me aproximado pela questão da luta, dizia..., "ah que bom tem música também”, mas era como se fosse uma coisa ao lado, paralela. Depois, praticando, entendi que as duas coisas eram a mesma coisa. Então a partir de aí minha atitude com a música de capoeira mudou (MARCO L., 2016, trad.minha).

Da mesma maneira, Tiziana relata ter começado atraída pela parte física da capoeira, sua componente esportiva, no entanto, foi se dando conta das possibilidades musicais da capoeira e, diz ela: "na verdade eu me apaixonei realmente quando percebi que também poderia aprender a tocar e cantar, e havia todo um conjunto de coisas" (TIZIANA, 2016, trad.minha). Emanuela Tamburri lembra que uma das coisas que mais a impressionou foi a música e o fato de poder aprender a tocar. Sua experiência com a arte musical não tinha sido das mais fáceis, ela conta ter sofrido um pequeno trauma. "Lembro-me que eu passei dias com o solfejo e o odiava totalmente, por isso, senti um repúdio pela música. Em vez disso, vi que poderia fazer música de uma forma diferente e, por isso, gostei. Uma maneira um pouco mais básica, mais intuitiva, então, esta coisa me impressionou muito (EMANUELA, 2015, trad.minha).

Segundo diversos relatos, na Itália como em outros países europeus, os adultos, mas também algumas crianças, sentem dificuldade emocional em cantar ou tocar por medo de errar, por conta da ideia difusa que para cantar é necessário se alcançar algum padrão estético de beleza, de afinação padronizada. O medo de errar é mais forte que a vontade de brincar: "Muitos com a parte musical quase se aterrorizam, porque são tímidos, devem derrubar a timidez", relata Tiziana (2016, trad.minha). Como aponta Blacking (1986, p. 67) devemos nos concentrar na experiência musical da capoeira como capaz de 
envolver as pessoas numa dimensão comunitária, parte de uma humanidade harmoniosamente organizada, e, então, expressão de um percurso de aprendizado.

O interesse pela diversidade cultural, especialmente por musicalidades diferentes das propostas pelos meios de massa e por um aprendizado corporal que envolve a música, foram aspetos de grande atrativo para o público da capoeira na Itália.

Aqui havia um interesse de curiosidade e passeando e frequentando a vários ambientes se entrava em contato com a musicalidades diferentes que não era a música pop, a música punk, não era o rap, não era a música clássica, mas eram outras tradições. Então, esse aspecto foi muito forte, porque atuava também como uma clara distinção entre a prática física, a capoeira, e todas as outras práticas físicas que um podia fazer nas academias de ginástica, as artes marciais chinesas, japonesas...este elemento de música (MARCO L., 2016, trad. minha).

Para finalizar, o contato com a capoeira mostrou aos italianos que o Brasil é muito mais complexo, respeito ao Brasil do carnaval, da alegria, da diversão que é mais facilmente divulgado aos italianos. A capoeira se desenvolveu como um canal de educação e de circulação de ideias e histórias independentes. Proporcionou uma relação direta com o povo brasileiro estimulando um confronto e um diálogo intercultural atual, que encheu lacunas educativas que não puderam ser aprofundadas nas instituições escolares.

\section{0 ritual da roda, o corpo em movimento na dimensão circular}

A capoeira angola pensada como uma performance ritual de grupo ofereceu aos italianos um aprendizado sobre eles mesmos e sobre formas de se organizar alternativas. Segundo o relato de todos os capoeiristas italianos com os quais me confrontei, essa prática, graças à dimensão repetitiva do ritual e ao olhar coletivo na roda, ofereceu novos instrumentos de análise das relações e de um mesmo. Segundo Marco V. (2015, trad.minha) a capoeira angola [...] me oferece uma direção / caminho para a vida de todos os dias". A curiosidade, a vontade de participar a algo diferente do estabelecido pelas mídias de massa e pelos circuitos comerciais, o desejo de se confrontar com outras culturas e a necessidade de se envolver em uma atividade que permitisse uma descoberta de si, através de uma prática ritual, são fatores que levaram todos os capoeiristas italianos com que conversei a se envolver com a capoeira. 
Antes de eu começar capoeira jogava futebol, que é uma grande paixão minha, quando posso ainda jogo, mas eu nunca pensei que poderia encontrar uma atividade que me envolvesse por tão longo período de tempo. Pensei que eu começaria fazendo um ano, 6 meses... Então eu conheci capoeira ... sua integralidade, o disse o mestre [Moraes]... que envolve o corpo, mente e alma. Provavelmente, outras disciplinas também ... Mas eu ... essa realmente completude e esta profundidade em conhecer a história, do passado, o que está por trás disso, como evoluiu... Mesmo um pouco o mistério da como evoluiu, o fato de que muitas coisas ainda não são claras, as muitas mudanças que ocorreram nos séculos. Então, o que eu realmente acho, é que é uma coisa que pode ser para a vida, porque envolve a alma. Este envolvimento que a mesma música tem um papel muito forte nesse sentido, eu acho que isso é o que realmente me fez apaixonar por capoeira esta completude, essa profundidade e este envolvimento que tenho notado ao longo dos anos um envolvimento, felizmente eu digo, porque a vida também é feita destas coisas, não só de alegria e felicidade, mas que a capoeira te cobra mesmo nos momentos de ... te leva para cima e leva-o para baixo, são momentos de ...., digamos acompanha a tua vida. Te acompanha e ajuda... (FABRIZIO, 2015, trad.minha).

Mesmo sendo uma prática culturalmente distante do universo italiano, a capoeira, traduzida com as problemáticas sociais e emocionais nacionais, auxiliou os capoeiristas com os quais conversei nos momentos de fragilidade emotiva, orientando-os para a vida em sociedade. A história de Alessandro é estreitamente ligada com esse percurso de formação.

Primeiro a minha situação pessoal era que eu estava ocupando centros sociais, organizava manifestações, acabei em uma situação de processos, etc.... Em que mesmo a minha família não me apoiava. Isolado e...de uma maneira violenta, no final as ocupações os despejos são uma forma violenta de ser, não há outra maneira, a polícia é violenta, se entra naquela espiral...e a capoeira me deu uma espécie de calma. Reconheço, após o tempo de trabalho, que a capoeira me tirou de lá e me colocou de volta em jogo em outro lugar. Eu não sei se é ela quem escolhe, dizem que é assim, mas eu acho que é uma questão de trocas, quanto mais você acredita nela, mais ela vai te dar, porque, obviamente, você é o cara que a leva aí, você não é um turista em capoeira, você é aquele que sofre, porque a verdade é que a capoeira traz tanta alegria no momento, mas o resto do tempo não é uma coisa feliz. Você sempre quer que seja melhor, que o aluno tenha entendido. Você mesmo queria seria melhor. Você gostaria 
de tantas coisas, por isso, não as tem nunca e provoca uma sensação de tristeza, de sofrimento entre aspas (ALESSANDRO, 2015, trad.minha).

Os depoimentos de Francesca e de Emanuela também reforçam essa componente emotiva, de conhecimento de si, no aprendizado da capoeira.

Em primeiro lugar a gerir as minhas emoções, conhecer-me melhor, saber me relacionar com os outros e a mostrar as garras quando necessário, a ser mais desperta na vida para algumas coisas. Para fazer algo que me faz sentir bem, eu sinto que se eu fizer isso bem feito também ajuda nisso. Para continuar a tradição, no sentido de assegurar que a tradição esteja também na Itália, e de uma maneira boa e limpa. Então, com o meu compromisso sinto que a capoeira me dá algo, mas na minha pequena maneira eu posso dar algo de volta à capoeira (FRANCESCA, 2015, trad.minha).

A segunda razão pela qual eu permaneci, talvez porque entrava num humor negativo e em um momento mudava tudo. Assim, nos últimos anos, tenho tido um trabalho de introspecção...ou seja difícil trabalhar, por dizer, a raiva, o controle emocional, o nervosismo e para mim, foi um lugar onde pude fazer isso (EMANUELA, 2015, trad.minha).

O interesse por novas perspectivas de aprendizado foi outro elemento fundamental. Mariagrazia acostumada com esportes competitivos, se interessou pela capoeira, porque lhe ofereceu uma maneira diferente de entender o diálogo corporal marcial, não baseado no ganhar e perder, mas no jogo e na música: "Esse período da minha vida era só capoeira, e claro, trabalho. Me tomou pelo completo, por muitos pontos de vista." (MARIAGRAZIA, 2016, trad.minha). Outro aspecto destacado foi a possibilidade de aprender a usar o corpo de uma maneira diferente do cotidiano: "trivialmente, de cabeça para baixo. Eu acho que há um benefício para o corpo, o humor, para usar o corpo, vê-lo em uma situação diferente" (MARCO R., 2016, trad.minha). A pesquisa do universo corporal, através de uma prática interdisciplinar, envolveu os italianos na a possibilidade de aprender aspectos culturais, musicais, antropológicos, aprender a língua portuguesa, além de desenvolver a criatividade e a movimentação física. Desenvolvendo, através da capoeira, um “intercâmbio físico, mas também cultural e humano "(MARCO M., 2015, trad.minha).

Outra componente muito importante para o desenvolvimento da capoeira na Itália é sem dúvida a da sociabilidade. Os grupos de capoeira são lugares de 
socialização, cujos membros desenvolvem grandes amizades pelas fortes emoções que compartilham durante aulas e rodas. "Somos um grupo de pessoas unidas pela mesma paixão, a gente sai junto, nós enfrentamos, brigamos, jogamos, assim como uma família e, por isso, eu acho também bom isso do capoeira, esta comunidade de pessoas que estão bem integradas" (TIZIANA, 2016, trad.minha). Aprender capoeira angola tem proporcionado a essas pessoas estar bem com elas mesmas e com os outros; esse tem sido um elemento fundamental para o desenvolvimento da capoeira na Itália.

As dificuldades as crises são parte desse percurso de aprendizado. Quase todos os capoeiristas com os quais conversei que pesquisam capoeira há mais de quinze anos, procuraram substituir a capoeira com outras atividades, mas sentindo-se quase que amarrados com ela, se viram constantemente obrigados a pesquisar mais, seguir adiante. Fabrizio ressaltou essa profunda relação entre o estado de crise e a criatividade, uma necessidade de renovação que permite dar continuidade a esse constante aprendizado. Mariagrazia também ressaltou esse aspecto da crise e, em sua fala, faz transparecer a importância da capoeira para uma geração que procurou entregar-se a ela.

É como um fio, como um cordão umbilical que nunca você vai querer quebrar. Durante muitos anos o meu interesse nunca caiu, teve momentos de baixa ... como dizer ... você perde um pouco a paixão por alguns momentos, mas depois volta, então, de repente volta, você não pode ficar sem, é quase viciante, como uma droga. Um pouco porque fazer capoeira é uma maneira de canalizar a tua energia e acho que é muito confortável [...] Tem pessoas que como eu fazem capoeira há muitos anos, as encontro nas oficinas, somos sempre nós, depois de tantos anos, com algumas rugas a mais, e não desistimos (MARIAGRAZIA, 2016, trad.minha).

No relato que segue, Marco L., falando sobre o que o levou a se envolver com a capoeira durante muitos anos, lembra que seus interesses mudaram conforme seu desenvolvimento. Ao chegar à Itália, a capoeira começou a ocupar o corpo dos italianos, se adaptar a seus interesses e gostos, ampliando seu leque de possibilidades, mostrando outros caminhos de vida, ampliando sua criatividade. Participando dos momentos de união e crescimento, de crise e decepção, aos poucos, essas pessoas têm construído ou traduzido uma capoeira angola que se tornou parte do seu cotidiano. "Uma parte de minha vida e, então, é uma coisa a qual eu não tenho intenção alguma de renunciar 
[...] um exercício contínuo de conhecimento de mim e dos outros" (MARCO L., 2016, trad.minha).

\section{Considerações finais}

A capoeira tem se instalado como sistema de comunicação entre línguas e culturas diferentes, pertencentes a dois países distantes. Em um primeiro momento, essas pessoas não tiveram a possibilidade de se conhecer cada um em seu contexto. Os primeiros capoeiristas brasileiros que chegaram na Itália não falavam italiano. Assim como os primeiros italianos que se interessaram pela capoeira na Itália não falavam português. A dinâmica ritual e corporal tem sido um ponto de comunicação e contato importante.

A capoeira angola tem sido para os italianos um canal de transmissão de conhecimentos alternativos aos main stream, eventualmente se se opondo a eles. Em um contexto distante daquele brasileiro, os italianos têm se apropriado dessa arte não apenas para conhecer outra cultura, mas colocaram em prática os ensinamentos apreendidos a partir d e sua releitura. As questões raciais, centrais para o discurso e a prática política da capoeira angola, por seu conteúdo etno-semântico e político-ideológico (Munanga, 2003), embora continuem a ser presentes, inevitavelmente, se tornaram secundárias. A capoeira angola como prática de libertação tomou a centralidade do discurso.

Nesse processo, em busca de novos encontros que oferecessem saídas para opressões que caracterizam a sociedade italiana, o etnocentrismo implícito nos italianos, viu-se em alguns casos reforçado. No entanto, hoje a capoeira angola interessa um público italiano cada vez mais restrito, um nicho dos que a conheceram no final dos anos noventa e primeira década de 2000 continuam apaixonados por ela, mas não envolve da mesma maneira os jovens de hoje. $\mathrm{O}$ entusiasmo desses italianos, assim como de outros estrangeiros, contribuiu para a renovação do interesse dos brasileiros para a capoeira, que tomada uma relevância internacional, se tornou fonte de interesse das novas gerações no Brasil, onde continua a ser massivamente praticada e pesquisada. $\mathrm{O}$ que me interessa sublinhar especialmente nesse artigo são algumas relações entre culturas, sempre criativas, feitas de encontros e desencontros, subversões e reproduções.

A capoeira angola, na Itália, tem um desenvolvimento muito recente; ela está sendo praticada desde um máximo duas décadas e com frequência é orientada por pessoas que não têm experiência para isso. Fato que reflete em dificuldades técnicas musicais e corporais, bem como em incompreensões na 
organização e no gerenciamento do ritual. Em suprimento a essas carências, que não são prerrogativas dos grupos estrangeiros mas podem ser observadas também, no Brasil, em grupos que não recebem a orientação adequada, a capoeira angola está se desenvolvendo com caraterísticas próprias que se aproximam mais do cotidiano e da experiência de vida dos italianos. No entanto, a relação foi criada e se continuar a ser desenvolvida com paixão e dedicação vai continuar mudando, mostrando que os aspectos subjetivos da capoeira são indetermináveis e contraditórios.

\section{Referências}

BLACKING John.

(1986). Come è musicale l'uomo? Milano: Unicopoli.

COLOSSEO.

(1996). Colosseo Rock, c'è anche Gabriel. La Repubblica, 26 out. 1996.

CARNEIR0 Edison de Souza.

(1991). Negros Bantos: Notas de etnografia religiosa e de folclore. Rio de Janeiro: Editora Civilização Brasileira.

(1977). Capoeira - Cadernos de Folclore. $2^{\mathrm{a}}$ edição.

(1971). Folguedos tradicionais. Rio de Janeiro: Conquista.

CASCUDO Luis da Câmara.

(1967). Folclore do Brasil. Rio de Janeiro: Editôra Fundo de Cultura.

CRIPPA Valeria.

(1995). Suoni e colori esotici sul palcoscenico del Lirico dopo Natale. "Oba Oba" ed è festa: arriva lo spettacolo con le belle ragazze brasiliane. Corriere della Sera, Milano, 21 dic. 1995, p. 51.

MARTORANA Marina.

(1994). Da San Siro a Novegro, una festa tira l'atra. L'estate diventa più esotica con ritmi e ricette tropicali. Corriere della Sera, Milano, 9 jul.1994, p. 51.
PORRO Maurizio.

(1984). Un tuffo folck nel Brasile e ricco di samba. Corriere della Sera: Milano, 13 dic. 1984, p. 23.

(1993). Magica samba, che fai ancora seognare il cummenda. Corriere della Sera: Milano, 23 dic. 1993, p. 31.

(1995). Oba Oba, il Brasile Sognato. Corriere della Sera, Milano, 30 dic. 1995, p. 39.

QUERINO Manuel Raimundo.

(1955). A Bahia de outrora. S/ed. Salvador.

RAMOS Arthur.

(1935). O Folk-Lore Negro do Brasil, p. 129. Rio. (1956). O negro na civilização brasileira. Rio de Janeiro: Editora CEB.

\section{Entrevistas:}

Entrevistadora: Cecilia Tamplenizza

ALESSANDR0, M., (8 agosto 2015), Cremona, Italia.

ALESSANDR0, M., (maggio 2021), online.

ALICE B., e EMANUELA T., (2 agosto 2015), Cremona, Italia.

ALICE B., (maggio 2021), online.

EMANUELA T., (maggio 2021), online.

FABRIZIO, P., (2 agosto 2015), Cremona, Italia. 
FABRIZI0, Z., (8 maggio 2016), Cremona, Italia. FABRIZIO, Z., (maggio 2021), online.

FRANCESCA, S., (2 agosto 2015), Cremona, Italia. FRANCESCA, S., (maggio 2021), online.

MARC0, L., (15 gennaio 2015), Milano, Italia.

MARC0, L., (maggio 2021), Milano, Italia.

MARCO, M., (1 agosto 2015), Cremona, Italia.

MARCO, M., (maggio 2021), online.

MARCO, R., (8 maggio 2016), Cremona, Italia.

MARC0, R., (maggio 2021), online.
MARC0, V., (1 agosto 2015), Cremona, Italia.

MARC0, V., (maggio 2021), online.

MARIAGRAZIA, S., (7 maggio 2016), Cremona, Italia.

MARIAGRAZIA, S., (maggio 2021), online.

TIZIANA, B.., (24 maggio 2016), Cremona, Italia.

TIZIANA, B., (maggio 2021), online.

\section{Recebido em}

julho de 2021

\section{Aprovado em}

dezembro de 2021 